21. Li, S., Cullen, W. K., Anwyl, R. \& Rowan, M. J. Dopamine-dependent facilitation of LTP induction in hippocampal CA1 by exposure to spatial novelty. Nature Neurosci. 6, 526-531 (2003).

22. Riedel, G. et al. Reversible neural inactivation reveals hippocampal participation in several memory process. Nature Neurosci. 2, 898-905 (1999).

23. Frankland, P. W., O'Brien, C. O., Ohno, M., Kirkwood, A. \& Silva, A. J. Alpha-CAMKII-dependent plasticity in the cortex is required for permanent memory. Nature 411, 309-313 (2001).

24. Siapas, A. G. \& Wilson, M. A. Coordinated interactions between hippocampal ripples and cortical spindles during slow-wave sleep. Neuron 21, 1123-1128 (1998)

25. Sirota, A., Csicsvari, J., Bhul, D. \& Buzsaki, G. Communication between neocortex and hippocampus during sleep in rodents. Proc. Natl Acad. Sci. USA 100, 2065-2069 (2003).

26. Wilson, M. A. \& McNaughton, B. L. Reactivation of hippocampal ensemble memories during sleep. Science 265, 676-679 (1994)

27. Lee, A. K. \& Wilson, M. A. Memory of sequential experience in the hippocampus during slow wave sleep. Neuron 36, 1183-1194 (2002).

Supplementary Information accompanies the paper on www.nature.com/nature.

Acknowledgements We thank T. Siapas, G. Laurent, M. Sutton and other members of the Schuman laboratory for discussions. This work was supported by the Fundacao para a Ciencia e Technologia (FCT)_Portugal and the Howard Hughes Medical Institute.

Competing interests statement The authors declare that they have no competing financial interests.

Correspondence and requests for materials should be addressed to E.M S. (schumane@its.caltech.edu).

\section{Enhanced virulence of influenza A viruses with the haemagglutinin of the 1918 pandemic virus}

\author{
Darwyn Kobasa $^{1 \star}$, Ayato Takada ${ }^{2,3}$, Kyoko Shinya $^{2 \star}$, Masato Hatta ${ }^{1}$, \\ Peter Halfmann ${ }^{1}$, Steven Theriault ${ }^{4}$, Hiroshi Suzuki ${ }^{5}$, \\ Hidekazu Nishimura ${ }^{6}$, Keiko Mitamura ${ }^{7}$, Norio Sugaya ${ }^{7}$, Taichi Usui ${ }^{8}$, \\ Takeomi Murata $^{8}$, Yasuko Maeda ${ }^{2}$, Shinji Watanabe ${ }^{1}$, M. Suresh $^{1}$, \\ Takashi Suzuki $^{3,9}$, Yasuo Suzuki ${ }^{3,9}$, Heinz Feldmann ${ }^{4}$ \\ \& Yoshihiro Kawaoka ${ }^{1,2,3}$
}

${ }^{1}$ Department of Pathobiological Sciences, University of Wisconsin, Madison, Wisconsin 53706, USA

${ }^{2}$ Division of Virology, Department of Microbiology and Immunology, Institute of Medical Science, University of Tokyo, Tokyo 108-8639, Japan

${ }^{3}$ CREST, Japan Science and Technology Agency, Saitama, 332-0012, Japan ${ }^{4}$ Special Pathogens Program, National Microbiology Laboratory, Health Canada and Department of Medical Microbiology, University of Manitoba, Winnipeg, Manitoba R3E 3R2, Canada

${ }^{5}$ Department of Public Health, School of Medicine, Niigata University, Niigata, 951-8510, Japan

${ }^{6}$ Viral Research Center Clinical Research Division, Sendai National Hospital, Sendai, 983-8520, Japan

${ }^{7}$ Department of Pediatrics, Nippon Kokan Hospital, Kawasaki, 210-0852, Japan ${ }^{8}$ Department of Applied Biological Chemistry, Shizuoka University, Shizuoka 422-8529, Japan

${ }^{9}$ Department of Biochemistry, University of Shizuoka, School of Pharmaceutical Sciences and COE Program in the 21st Century, Yada, Shizuoka-shi 422-8526, Japan

* Present addresses: National Microbiology Laboratory, Canadian Science Centre for Human and Animal Health, Winnipeg, Manitoba R3E 3R2, Canada (D.K.); Institute for Animal Experimentation, Tohoku University Graduate School of Medicine, Sendai 980-8575, Japan (K.S.); Department of Pediatrics, Kawasaki Municipal Hospital, Kawasaki 210-0013, Japan (K.M.); Department of Pediatrics, Keiyu Hospital, Yokohama 220-0012, Japan (N.S.)

The 'Spanish' influenza pandemic of 1918-19 was the most devastating outbreak of infectious disease in recorded history. At least 20 million people ${ }^{1}$ died from their illness, which was characterized by an unusually severe and rapid clinical course. The complete sequencing of several genes of the 1918 influenza virus has made it possible to study the functions of the proteins encoded by these genes in viruses generated by reverse genetics, a technique that permits the generation of infectious viruses entirely from cloned complementary DNA. Thus, to identify properties of the 1918 pandemic influenza A strain that might be related to its extraordinary virulence, viruses were produced containing the viral haemagglutinin ${ }^{2}$ (HA) and neuraminidase ${ }^{3}$ (NA) genes of the 1918 strain. The HA of this strain supports the pathogenicity of a mouse-adapted virus in this animal ${ }^{4,5}$. Here we demonstrate that the HA of the 1918 virus confers enhanced pathogenicity in mice to recent human viruses that are otherwise non-pathogenic in this host. Moreover, these highly virulent recombinant viruses expressing the 1918 viral HA could infect the entire lung and induce high levels of macrophage-derived chemokines and cytokines, which resulted in infiltration of inflammatory cells and severe haemorrhage, hallmarks of the illness produced during the original pandemic ${ }^{6}$.

The sequence of the HA receptor/fusion gene of the 1918 influenza A virus $\left(\mathrm{H}^{\mathrm{sp}}\right)$ was determined in 1999 (ref. 2), followed shortly by the NA gene $\left(\mathrm{N}^{\mathrm{sp}}\right)^{3}$, which codes for the viral sialidase. These molecules, which represent the major viral surface glycoproteins of influenza virus, are important targets of the host immune response, and critical changes in their structure can expand the viral host range and enhance the virulence of infection ${ }^{7,8}$. However, neither protein of the 1918 virus contains sequence motifs known to be associated with high virulence ${ }^{2,3}$. Attempts to account for the unusually high virulence of the virus have focused on the living conditions of soldiers, a highly susceptible group, and of civilians at the end of the First World War ${ }^{9}$, as well as on potentially unique properties of the virus itself $\mathrm{f}^{10,11}$. The combination of $\mathrm{H}^{\mathrm{sp}}$ and $\mathrm{N}^{\mathrm{sp}}$ in an $\mathrm{A} / \mathrm{WSN} / 33$ (WSN) (H1N1) genetic background was shown to be pathogenic in mice without prior adaptation of the proteins to growth in these hosts ${ }^{4,5}$, usually a prerequisite for producing a lethal infection in mice with a human virus. However, WSN itself is both adapted to and highly pathogenic in mice, so it was not possible to assess the possible contribution that $\mathrm{H}^{\mathrm{sp}}$ and $\mathrm{N}^{\mathrm{sp}}$ had made to the pathogenicity of the recombinant virus. Another candidate, the non-structural gene of the 1918 virus, had an attenuating effect when tested in a recombinant virus bearing the genetic background of A/Puerto Rico/8/34 (H1N1), also a highly pathogenic virus in mice ${ }^{10}$. Viruses generated with the matrix, nucleoprotein and non-structural protein genes of WSN replaced by the respective genes from the 1918 virus, together with $\mathrm{H}^{\mathrm{sp}}$ and $\mathrm{N}^{\mathrm{sp}}$, were also pathogenic in mice ${ }^{4,5}$ but not significantly more than the recombinant possessing only the $\mathrm{H}^{\mathrm{sp}}$ and $\mathrm{N}^{\mathrm{sp}}$ genes. Thus, the molecular basis for the unprecedented virulence of the 1918 pandemic virus remains uncertain, opening the way for studies that directly test the contribution of $\mathrm{H}^{\mathrm{sp}}$ and $\mathrm{N}^{\mathrm{sp}}$ to pathogenicity.

We therefore used reverse genetics ${ }^{12}$ to produce a panel of recombinant viruses containing $\mathrm{H}^{\mathrm{sp}}$ together with $\mathrm{N}^{\mathrm{sp}}$ or the NA gene of A/Kawasaki/173/2001 (H1N1) (K173) in the background of the remaining negative-sense RNA gene segments derived from three influenza viruses: WSN, K173 and A/Memphis/8/88 (H3N2) (M88) (Table I). All recombinant viruses formed plaques on Madin-Darby canine kidney (MDCK) cell monolayers in the presence of trypsin and replicated efficiently to a high titre (data not shown).

To assess the contribution of $\mathrm{H}^{\mathrm{sp}}$ and $\mathrm{N}^{\mathrm{sp}}$ to pathogenicity in vivo, mice were intranasally inoculated with the recombinant and parental viruses. Each virus possessing $\mathrm{H}^{\mathrm{sp}}$ as well as the WSN virus replicated to a high titre in the lungs by day 3 post-infection (p.i.; Table I) and was pathogenic, resulting in serious morbidity and eventually death. Notably, the K173 and M88 parental human viruses did not cause discernible morbidity in mice and replicated to only low titres in the lungs, whereas the $\mathrm{K} 173 / \mathrm{H}^{\mathrm{sp}}$ and $\mathrm{M} 88 / \mathrm{H}^{\mathrm{sp}}$ viruses, in which the original HA proteins were replaced with $\mathrm{H}^{\mathrm{sp}}$, caused lethal infection in mice. The $\mathrm{N}^{\mathrm{sp}}$ protein did not contribute to viral pathogenicity, as viruses containing $\mathrm{H}^{\mathrm{sp}}$ and $\mathrm{N}^{\mathrm{sp}}$ were not 
more pathogenic than those with the K173 NA. By contrast, the HA and NA proteins of WSN did not significantly enhance the virulence of either M88 or K173, as indicated by the lack of illness in mice inoculated with recombinant $\mathrm{M} 88 / \mathrm{HN}^{\mathrm{WSN}}$ and limited illness associated with $\mathrm{K} 173 / \mathrm{HN}^{\mathrm{WSN}}$ infection. The ability of WSN/ $\mathrm{H}^{\mathrm{sp}} \mathrm{N}^{\mathrm{sp}}$ ( $\mathrm{H}^{\mathrm{sp}}$ and $\mathrm{N}^{\mathrm{sp}}$ in the WSN background) and WSN to replicate in organs outside the respiratory tract was also assessed, with no evidence of replication detected in the heart, spleen, liver, kidneys or brain. Intracerebral inoculation of mice with $6 \times 10^{5}$ plaqueforming units (PFU) of WSN, WSN/ $\mathrm{H}^{\mathrm{sp}} \mathrm{N}^{\mathrm{sp}}$ or $\mathrm{K} 173 / \mathrm{H}^{\mathrm{sp}} \mathrm{N}^{\mathrm{sp}}\left(\mathrm{H}^{\mathrm{sp}}\right.$ and $\mathrm{N}^{\text {sp }}$ in the K173 background) led to replication of only WSN in the brain (data not shown), an outcome consistent with the capacity of plasminogen binding by the NA to activate the HA and increase the neurotropism of $\mathrm{WSN}^{13}$, properties not shared by the NA protein of either the K173 or the 1918 virus. The relative pathogenicities of the viruses bearing $\mathrm{H}^{\mathrm{sp}}$ depended on the type of virus providing the other gene segments. For $\mathrm{WSN} / \mathrm{H}^{\mathrm{sp}} \mathrm{N}^{\mathrm{sp}}$ the dose required to kill $50 \%$ of infected mice $\left(\mathrm{MLD}_{50}\right)$ was similar to that of WSN (Table I). MLD 50 values for the other viruses were higher than for WSN/ $/ \mathrm{H}^{\mathrm{sp}} \mathrm{N}^{\mathrm{sp}}$, a reflection of the contribution of genes from the mouse-adapted WSN compared to the non-adapted human viruses. Thus, it appears that $\mathrm{H}^{\mathrm{sp}}$ possesses unknown properties, not found in the WSN HA, that determine its ability to enhance the virulence of influenza $A$ viruses in mice.

In a further effort to understand the increased virulence of the 1918 virus, we examined the lungs of mice intranasally infected with $10 \mathrm{MLD}_{50}$ (see Methods for details of $\mathrm{MLD}_{50}$ calculation) of WSN, WSN/ $/ \mathrm{H}^{\mathrm{sp}} \mathrm{N}^{\mathrm{sp}}, \mathrm{M} 88 / \mathrm{H}^{\mathrm{sp}} \mathrm{N}^{\mathrm{sp}}$ ( $\mathrm{H}^{\mathrm{sp}}$ and $\mathrm{N}^{\mathrm{sp}}$ in the M88 background) or $\mathrm{M} 88 / \mathrm{H}^{\mathrm{sp}}$, or a dose of M88 that was equivalent (in PFU) to $10 \mathrm{MLD}_{50}$ of $\mathrm{M} 88 / \mathrm{H}^{\mathrm{sp}} \mathrm{N}^{\mathrm{sp}}$ (as M88 was not lethal). By day 6 p.i. the viral antigen distribution for $\mathrm{WSN} / \mathrm{H}^{\mathrm{sp}} \mathrm{N}^{\mathrm{sp}}, \mathrm{M} 88 / \mathrm{H}^{\mathrm{sp}} \mathrm{N}^{\mathrm{sp}}$ and $\mathrm{M} 88 / \mathrm{H}^{\mathrm{sp}}$ was considerably wider-encompassing the bronchus, bronchioli and almost the entire alveolar epithelium-than that seen for M88 or even WSN (Fig. 1a-c; see also Supplementary Figs 1 and 2; data for $\mathrm{M} 88 / \mathrm{H}^{\mathrm{sp}} \mathrm{N}^{\mathrm{sp}}$ not shown). Infection with viruses possessing $\mathrm{H}^{\mathrm{sp}}$ was characterized by massive recruitment of polymorphonuclear cells (mainly neutrophils) accompanied by intraalveolar haemorrhage (Fig. 1d; see also Supplementary Figs 1 and 2). M88, on the other hand, produced limited inflammatory foci that resulted from initial infection of the bronchioli with only minor extensions into the adjacent alveoli. Most of the lung had a similar appearance to normal, uninfected controls (Fig. 1e, f; see also Supplementary Fig. 1) and only limited viral antigen was detected (Fig. 1; see also Supplementary Fig. 1). The presence of $\mathrm{H}^{\mathrm{sp}}$ in $\mathrm{M} 88 / \mathrm{H}^{\mathrm{sp}}$ permitted greater viral replication over a longer period compared with M88, as shown by detection of viral antigen on day 6 p.i. (Fig. 1a, b), but the pathogenicity of viruses containing $\mathrm{H}^{\mathrm{sp}}$

\begin{tabular}{|c|c|c|c|c|c|}
\hline \multirow[b]{2}{*}{ Virus } & \multicolumn{3}{|c|}{ Origin of genes ${ }^{\star}$} & \multirow[b]{2}{*}{$\mathrm{MLD}_{50} \dagger$} & \multirow[b]{2}{*}{ Lung titref } \\
\hline & $\mathrm{HA}$ & NA & Others & & \\
\hline WSN/H $/ H^{s p} N^{s p}$ & 1918 & 1918 & WSN & 3.0 & $5.0 \pm 0.1$ \\
\hline WSN & WSN & WSN & WSN & 3.3 & $5.0 \pm 0.3$ \\
\hline $\mathrm{M} 88 / \mathrm{H}^{\mathrm{sp}} \mathrm{N}^{\mathrm{sp}}$ & 1918 & 1918 & M88 & 5.2 & $4.7 \pm 0.2$ \\
\hline $\mathrm{M} 88 / \mathrm{H}^{\mathrm{sp}}$ & 1918 & K173 & M88 & 4.4 & $5.1 \pm 0.1$ \\
\hline M88 & M88 & M88 & M88 & $>6.2$ & $2.9 \pm 0.2$ \\
\hline $\mathrm{M} 88 / \mathrm{HN}^{\mathrm{WSN}}$ & WSN & WSN & M88 & $>6.7$ & ND \\
\hline $\mathrm{K} 173 / \mathrm{H}^{\mathrm{sp}} \mathrm{N}^{\mathrm{sp}}$ & 1918 & 1918 & $\mathrm{~K} 173$ & 6.9 & ND \\
\hline $\mathrm{K} 173 / \mathrm{H}^{\mathrm{sp}}$ & 1918 & K173 & K173 & 5.2 & $4.8 \pm 0.2$ \\
\hline K173 & K173 & K173 & K173 & $>7.4$ & $3.5 \pm 0.3$ \\
\hline $\mathrm{K} 173 / \mathrm{HN}^{\mathrm{WSN}}$ & WSN & WSN & K173 & $>6.9$ & $\mathrm{ND}$ \\
\hline
\end{tabular}

ND, no data.

* Recombinant viruses were generated with gene segments from the 1918 pandemic virus, AWSN/ 33 (WSN), A/Memphis/8/88 (M88) and A/Kawasaki/173/2001 (K173).

†The virus dose required to kill $50 \%$ of mice $\left(M L D_{50}\right)$ was determined by intranasally inoculating mice with the test virus, as described in Methods.

$\ddagger$ Average $\left( \pm\right.$ s.d.) lung titres in three mice studied on day 3 p.i. expressed as $\log _{10}$ PFU per g lung tissue. was not related simply to the extent of viral replication. High titres of virus were recovered from the lungs of mice infected with both WSN and WSN/ $\mathrm{H}^{\mathrm{sp}} \mathrm{N}^{\mathrm{sp}}$ on both days 3 and 6 p.i., but lesions produced by WSN/ $\mathrm{H}^{\mathrm{sp}} \mathrm{N}^{\mathrm{sp}}$ in lung tissue were clearly more severe (Supplementary Table 1 and Supplementary Fig. 2a, b). The lungs of mice infected with WSN had the characteristics of bronchopneumonia, but inflammatory reactions and viral antigens were confined mainly to the bronchus, bronchioli and peribronchiolar alveoli. As the $\mathrm{M} 88 / \mathrm{H}^{\mathrm{sp}}$ recombinant, which possesses only the HA from the 1918 virus, caused severe lung infection similar to that seen with WSN/ $/ \mathrm{H}^{\mathrm{sp}} \mathrm{N}^{\mathrm{sp}}$ or $\mathrm{M} 88 / \mathrm{H}^{\mathrm{sp}} \mathrm{N}^{\mathrm{sp}}$ infection, these results indicate that $\mathrm{H}^{\mathrm{sp}}$ was the primary determinant of enhanced pathogenicity in the recombinant viruses. Severe lung infection was a hallmark of the illness produced by the original pandemic virus in humans ${ }^{6}$, suggesting a possible, although not conclusive, association between the pandemic virus HA and its pathogenicity in humans, and indicating the need to examine the contribution of the HA to viral pathogenicity in other animal models.

The severity of influenza-virus-induced disease in humans correlates with the ability of virulent viral strains to induce proinflammatory cytokines in macrophages ${ }^{14,15}$. Additionally, there is a strong association between cytokine levels and severity of clinical symptoms in people infected with influenza ${ }^{16-18}$. Therefore it is possible that pathogenicity of $\mathrm{H}^{\mathrm{sp}}$-expressing viruses might be causally related to their enhanced ability to induce pro-inflamma-
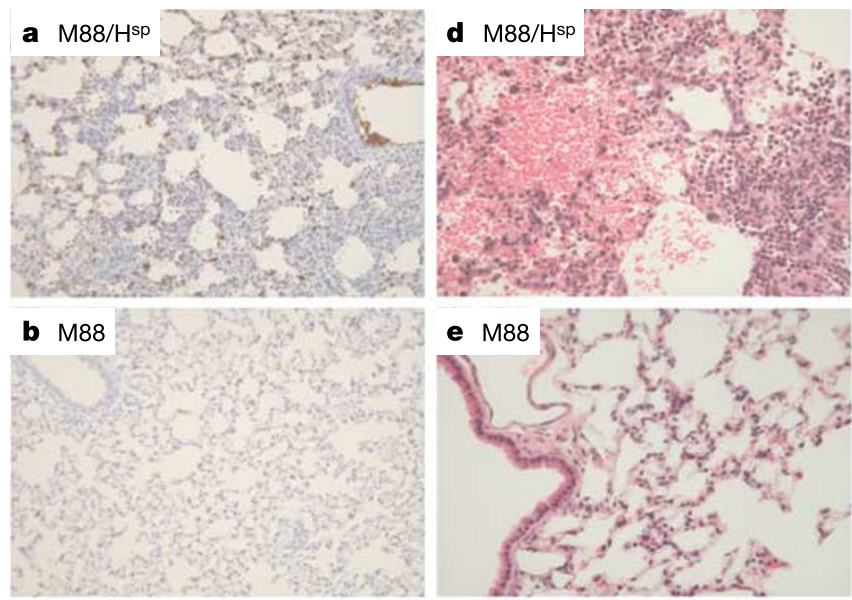

\section{c Control}
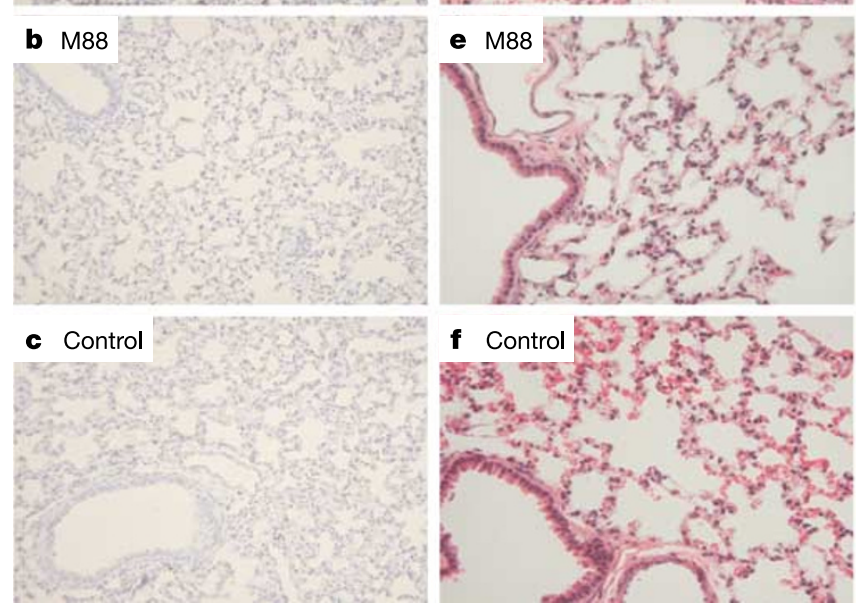

Figure 1 Pathological examination of lungs infected with the $M 88 / H^{s p}$ or M88 viruses a, Viral antigens were distributed throughout the entire lung of mice infected with $\mathrm{M} 88 / \mathrm{H}^{\mathrm{sp}}$, including the bronchiole and alveoli of all lobes. $\mathbf{b}$, By contrast, in lung tissue of mice infected with only the background virus $M 88$, viral antigens were not detected on day 6 p.i. d, Global severe inflammatory reactions extending from the bronchus to the bronchiole to the alveoli were prominent in the lungs of mice infected with $M 88 / H^{s p}$. Numerous neutrophilic infiltrations were prominent in the peribronchial area and alveolar wall. Haemorrhage and oedematous lesions were common. These observations contrast with the lungs of mice infected with M88, which produced only small, irregularly distributed inflammatory lesions that were self-limited. Indeed, the vast majority of the lung was not affected (e), similar to normal lung (f). a, d, M88/ $\mathrm{H}^{\mathrm{sp}}$, lung, 6 days p.i.; $\mathbf{b}, \mathbf{e}$, M88, lung, 6 days p.i.; $\mathbf{c}, \mathbf{f}$, control, lung. a-c, Immunostaining with a rabbit polyclonal antibody to WSN; $\mathbf{d}-\mathbf{f}$, haematoxylin and eosin staining. 
tory cytokines and inflict immune damage to tissues in infected mice. To probe this possibility, we compared levels of cytokines/ chemokines in lungs between viral isolates that differed in their virulence. Notably, the levels of monocyte chemotactic protein 1 (MCP-1), macrophage inflammatory protein (MIP)-1 $\beta$, MIP-2, MIP-3 $\alpha$, interleukin (IL)-1 $\beta$, IL-6, IL-12 (p40), IL-18 and granulocyte colony stimulating factor (G-CSF) in the lungs of $\mathrm{M} 88 / \mathrm{H}^{\mathrm{SP}}$ infected mice were substantially higher than in M88-infected mice (Fig. 3). Because activated macrophages are the major

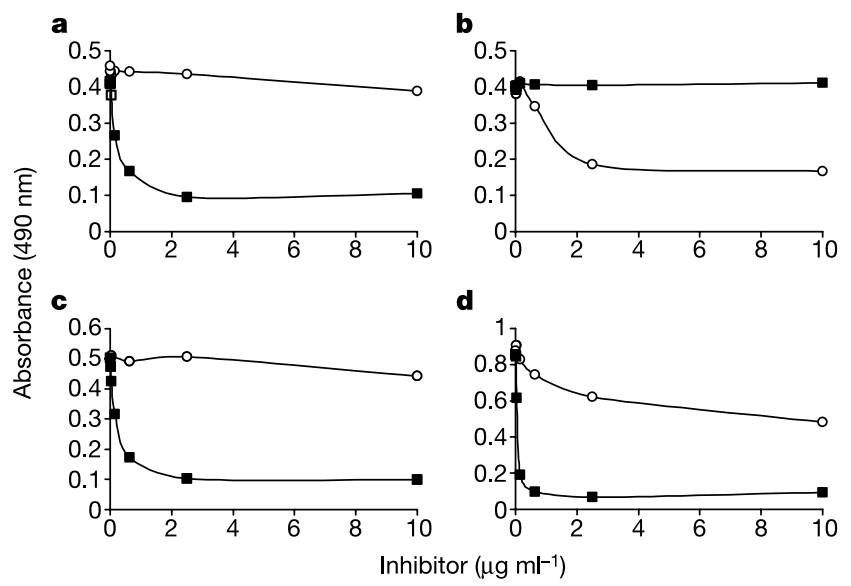

Figure 2 Competitive binding assay for haemagglutinin receptor specificity. a-d, The relative binding affinities of $\mathrm{HA}$ in viruses $\mathrm{WSN} / \mathrm{H}^{\mathrm{sp}} \mathrm{N}^{\mathrm{sp}}$ (a), $\mathrm{A} / \mathrm{dk} / \mathrm{HK} / 836 / 80(\mathbf{b})$, A/Kawasaki/173/01 (c) and A/New Caledonia/20/99 (d) were determined by competitive inhibition of HRP-conjugated fetuin binding by NeuAc 2 2,3Gal (open circles) or NeuAc $\alpha 2,6$ Gal (filled squares) sialylglycopolymers. source of IL-1 $\beta$, IL-6, IL-12, IL-18 and G-CSF during inflammation, the presence of high levels of these cytokines is strongly indicative of macrophage activation (Supplementary Fig. 3). Whereas the chemokines MCP-1, MIP- $1 \beta$ and MIP- $3 \alpha$ are capable of inducing mixed leukocyte recruitment to the site of inflammation, the strong induction of MIP-2 (a strong chemoattractant for neutrophils) is highly consistent with the infiltration of granulocytes in the lungs of $\mathrm{M} 88 / \mathrm{H}^{\mathrm{SP}}$-infected mice. Taken together, these data suggested that $\mathrm{H}^{\mathrm{sp}}$ is a critical determinant of macrophage activation, especially early on in infection (see day 1 data in Fig. 3), and of production of chemoattractant for neutrophils, which subsequently leads to the trafficking of neutrophils and acute lung injury ${ }^{19,20}$.

The 1918 virus is thought to have originated from an avian source $^{2}$. Hence, the relative ability of the HA to recognize the preferred receptor species for human viruses-sialic acid bound to a neighbouring galactose by an $\alpha 2,6$ linkage (NeuAc $\alpha-2,6 \mathrm{Gal})$ in contrast to the preferred avian virus receptor, NeuAc $\alpha-2,3 \mathrm{Gal}^{21}$-is thought to affect its ability to infect humans and cause disease. Using a competitive binding assay, we showed that the $\mathrm{H}^{\text {sp }}$ preferentially recognizes NeuAc $\alpha-2,6 \mathrm{Gal}$ (Fig. 2). Although humans possess both types of receptor species in respiratory epithelia and are susceptible to infection with viruses bearing HA proteins of either receptor specificity ${ }^{22}$, all of the human viruses studied thus far preferentially recognize NeuAc $\alpha-2,6 \mathrm{Gal}$ over NeuAc $\alpha-2,3 \mathrm{Gal}^{21}$. Thus, our data suggest that the virus that eventually became the 1918 pandemic strain must have circulated in humans, or possibly another adaptive host (such as pigs) with human-type receptors, for a sufficient time to develop a preference for the human sialic acid receptor. This model gains support from the recently solved crystal structure of $\mathrm{H}^{\mathrm{sp}}$ (refs 23,24$)$, which predicts that the protein would preferentially bind to the human receptor ${ }^{23}$.

An additional factor influencing the severity of an influenza pandemic or epidemic is the level of pre-existing immunity to the
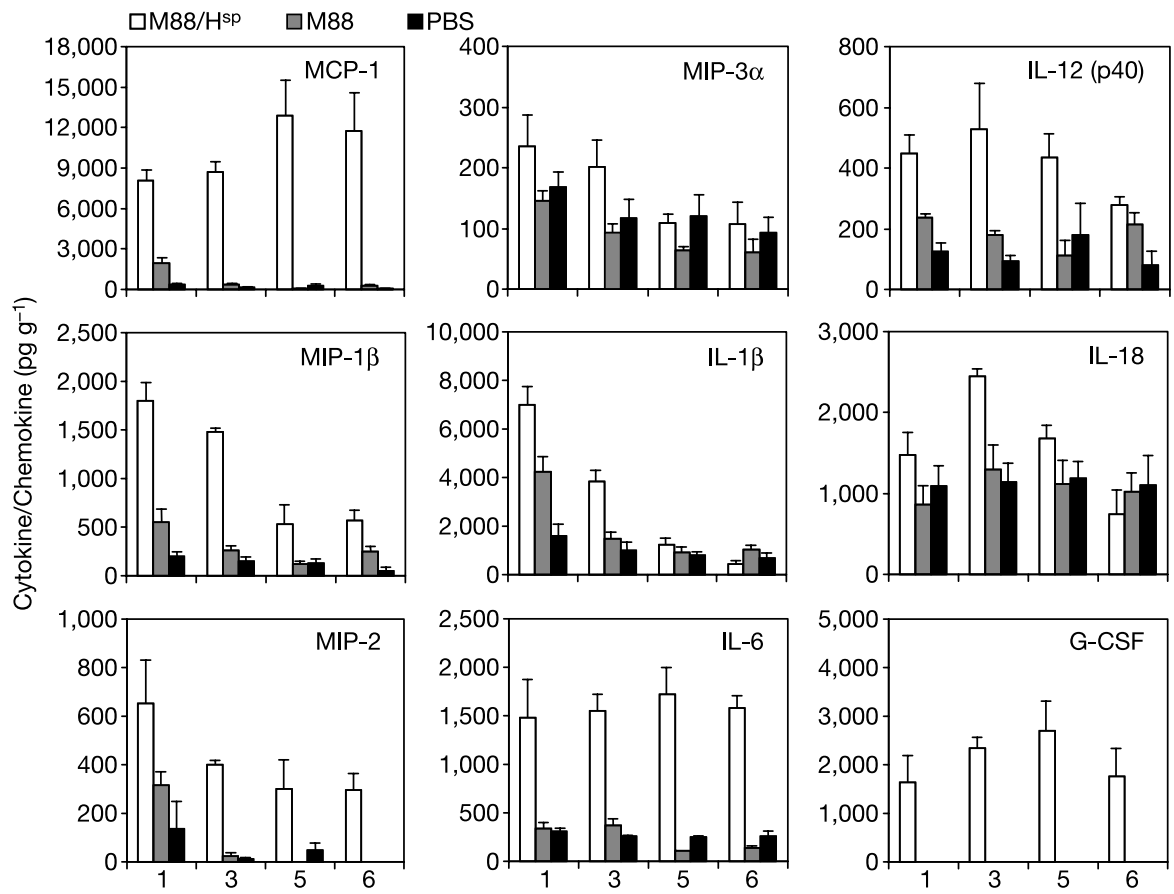

Days after infection

Figure 3 Cytokine expression in lungs of mice infected with $M 88 / \mathrm{H}^{\mathrm{sp}}$ and $\mathrm{M} 88$ or mock infected (PBS). The expression of cytokines and chemokines in lung homogenates was determined by ELISA on days 1, 3, 5 and 6 p.i. Data are presented as the mass of cytokine (pg) per $\mathrm{g}$ of lung tissue ( \pm standard deviation). (See also Supplementary Fig. 3.) 


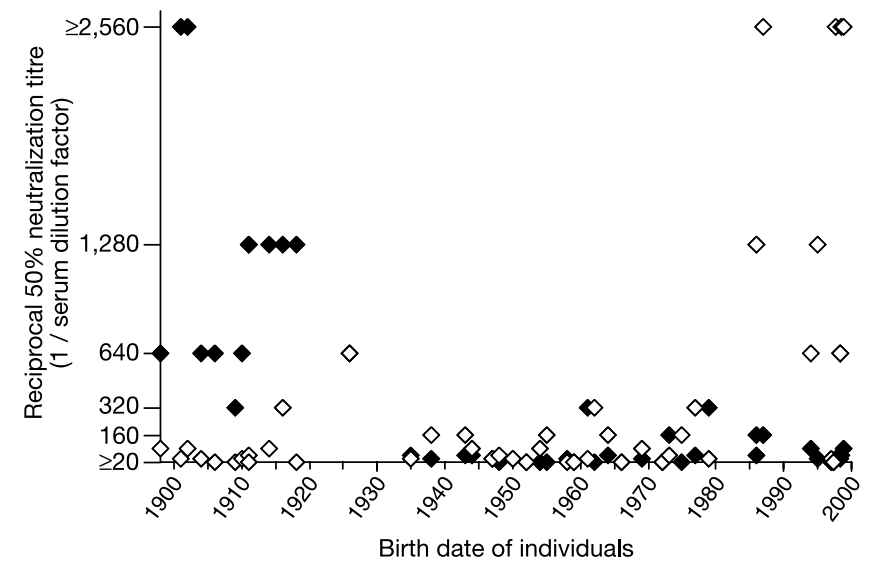

Figure 4 Neutralization activities in human sera against a virus possessing $\mathrm{H}^{\mathrm{sp}}$ and $\mathrm{N}^{\mathrm{sp}}$. Neutralization titres of sera from a broad cross-section of donors were measured against WSN $/ H^{\mathrm{Sp}} \mathrm{N}^{\mathrm{sp}}$ (filled diamonds) and a recent human H1N1 virus (open diamonds) in a plaque reduction assay. Donors younger than $14 \mathrm{yr}$ were recently infected with an H1N1 virus, with the exception of two cases of H3N2 infection. The history of influenza infection in other donors was unknown. The reciprocal titre of serum required to neutralize at least $50 \%$ of each virus ( $50 \%$ neutralizing titre) is plotted against the date of birth of the patients.

virus. To assess the extent to which the human population would be protected from the emergence of a 1918-like virus, we compared the neutralizing activities in a panel of human sera obtained in 1999 from patients of widely differing ages. The majority of the serum donors younger than $15 \mathrm{yr}$ of age, most of whom had recently been infected with an H1N1 virus, showed strong neutralizing activity against a recent $\mathrm{H} 1 \mathrm{~N} 1$ test virus, but only limited activity against the $\mathrm{WSN} / \mathrm{H}^{\mathrm{sp}} \mathrm{N}^{\mathrm{sp}}$ virus (Fig. 4; see also Supplementary Table 2). By contrast, serum samples from donors who were alive in 1918 showed markedly high activities against the $\mathrm{WSN} / \mathrm{H}^{\mathrm{sp}} \mathrm{N}^{\mathrm{sp}}$ virus compared with those against recent $\mathrm{H} 1 \mathrm{~N} 1$ and $\mathrm{H} 3 \mathrm{~N} 2$ isolates. Donors born between 1934 and 1978 had only limited neutralizing activity against the WSN $/ \mathrm{H}^{\mathrm{sp}} \mathrm{N}^{\mathrm{sp}}$ virus. Thus, a large segment of the population would be susceptible to an outbreak of a 1918-like influenza virus. The only group with significant natural protection would be survivors of the 1918 pandemic, who still express high levels of antibodies against an antigen to which they were exposed to over $80 \mathrm{yr}$ ago, a phenomenon referred to as original antigenic $\sin ^{25,26}$.

Analysis of sequence information derived directly from viral genes in the preserved tissues of people infected during the 1918 pandemic offers unparalleled opportunity to assess the contributions of the HA, NA and other viral proteins to the extreme virulence of this unique pathogen. Using a reverse genetics technique to generate a panel of reassortants containing different combinations of the $\mathrm{H}^{\mathrm{sp}}$ and $\mathrm{N}^{\mathrm{sp}}$ genes in varied genetic backgrounds, we show that the HA protein (but not the NA protein) from the 1918 virus is essential for highly virulent infection in an animal model. However, the virulence of influenza virus is probably a polygenic trait, in that ultimately we expect other gene products, such as the NS1 protein ${ }^{27}$, to be implicated in the phenotype of the 1918 virus. Sequence analysis of the $\mathrm{H}^{\text {sp }}$ gene by others suggests that it originated in birds ${ }^{2}$ and therefore is likely to be contained in viruses still circulating in the avian pool, where viral proteins remain relatively unchanged. Once the properties of the $\mathrm{H}^{\mathrm{sp}}$ gene that gave rise to its lethal infectivity are better understood, it should be possible to devise effective control measures and to improve global surveillance networks for influenza viruses that pose the greatest threat to humans as well as other animal species.

\section{Methods \\ Viruses}

Full-length HA (GenBank accession number AF117241) and NA (GenBank AF250356) genes from the 1918 influenza A virus were constructed by using successive polymerase chain reaction amplifications with 70-mer oligonucleotides and cloned into a plasmid vector (pPolI) containing the RNA polymerase I promoter and terminator to generate pPolI-1918HA and pPol-1918NA. Recombinant viruses WSN/ $\mathrm{H}^{\mathrm{sp}} \mathrm{N}^{\mathrm{sp}}, \mathrm{K} 173 / \mathrm{H}^{\mathrm{sp}} \mathrm{N}^{\mathrm{sp}}$, $\mathrm{K} 173 \mathrm{H}^{\mathrm{sp}}, \mathrm{M} 88 / \mathrm{H}^{\mathrm{sp}} \mathrm{N}^{\mathrm{sp}}, \mathrm{M} 88 / \mathrm{H}^{\mathrm{sp}}, \mathrm{K} 173 / \mathrm{HN}^{\mathrm{WSN}}, \mathrm{M} 88 / \mathrm{HN}^{\mathrm{WSN}}$ as well as parental viruses K173, M88 and WSN were generated by reverse genetics as previously described $^{12}$. Viruses were passaged twice on MDCK cells, in the presence of $1.0 \mu \mathrm{g} \mathrm{ml}^{-1}$ TPCK-treated trypsin in minimal essential medium (MEM) supplemented with $0.3 \%$ bovine serum albumin and antibiotics. Influenza viruses $\mathrm{A} / \mathrm{New}$ Caledonia/ 20/99 (H1N1) (NewCal), A/duck/Hong Kong/836/80 (H3N1) (dk/HK/80) and another recent clinical isolate, A/Kawasaki/233/2001 (H1N1) (K233), were similarly propagated in MDCK cells. All procedures related to viruses containing genes from the 1918 virus were performed in a Biosafety level 4 facility at the National Microbiology Laboratory, Health Canada, in Winnipeg, or in enhanced BSL3 at the University of Wisconsin-Madison.

\section{In vitro analysis of viral replication}

Semi-confluent MDCK cells were infected at a multiplicity of infection of $0.001 \mathrm{PFU}$ per cell with each virus maintained under the same growth conditions used for the propagation of viruses. The supernatant was sampled at times $0,15,24,39$ and $48 \mathrm{~h}$ p.i., and titres were determined by standard plaque assay on confluent MDCK cells in the presence of $1.0 \mu \mathrm{g} \mathrm{ml}^{-1}$ TPCK-trypsin. The results of duplicate assays are reported.

\section{HA receptor analysis by solid-phase binding assay}

Viruses were allowed to attach overnight at $4{ }^{\circ} \mathrm{C}$ in wells of 96-well plates as previously described ${ }^{28}$. Polymer-bound conjugates containing the sialic acid $\mathrm{N}$-acetylneuraminic acid linked to galactose through either an $\alpha-2,3$ or $\alpha-2,6$ bond (Neu5Ac $2,3 \mathrm{LacNAcb}-\mathrm{pAP}$ and Neu5Ac 2 2,6LacNAcb-pAP) were prepared as previously described ${ }^{29}$. Serial dilutions of each sialylglycoconjugate were prepared in phosphate-buffered saline (PBS) containing $0.01 \%$ Tween-20 (TPBS), and $25 \mu \mathrm{l}$ was added to the wells containing the immobilized viruses together with $25 \mu \mathrm{l}$ of $47 \mathrm{nM}$ horseradish peroxidase (HRP)-conjugated bovine fetuin in TPBS. After incubation at $4{ }^{\circ} \mathrm{C}$ for $2 \mathrm{~h}$, the wells were extensively washed with PBS, and $100 \mu \mathrm{l}$ per well of $o$-phenylenediamine $\left(0.4 \mathrm{mg} \mathrm{ml}^{-1}\right)$ in $0.02 \% \mathrm{H}_{2} \mathrm{O}_{2}, 50 \mathrm{mM}$ citrate-phosphate buffer, $\mathrm{pH} 5.5$ was added. After incubation at $25^{\circ} \mathrm{C}$ for $15 \mathrm{~min}$, the absorbance at $490 \mathrm{~nm}$ was read.

\section{Viral pathogenicity and lethal dose determination}

Isofluorane-anaesthetized 6-week-old female BALB/C mice were intranasally inoculated with tenfold serial dilutions (three mice per dilution) of viruses in $100 \mu \mathrm{l}$ of PBS. The mice were monitored daily for 21 days for disease symptoms and survival. The dose required to kill $50 \%$ of mice $\left(\mathrm{MLD}_{50}\right)$ was calculated by the method of ref. 30 .

To determine the extent of viral replication in mice, we intranasally inoculated animals with $10 \mathrm{MLD}_{50}$ of $\mathrm{M} 88 / \mathrm{H}^{\mathrm{sp}} \mathrm{N}^{\mathrm{sp}}, \mathrm{M} 88 / \mathrm{H}^{\mathrm{sp}}, \mathrm{K} 173 / \mathrm{H}^{\mathrm{sp}} \mathrm{N}^{\mathrm{sp}}, \mathrm{K} 173 / \mathrm{H}^{\mathrm{sp}}, \mathrm{WSN}$ or WSN $/ \mathrm{H}^{\mathrm{sp}} \mathrm{N}^{\mathrm{sp}}$, or with a dose of non-pathogenic virus, M88 or K173, equivalent in PFU to $10 \mathrm{MLD}_{50}$ of $\mathrm{M} 88 / \mathrm{H}^{\mathrm{sp}} \mathrm{N}^{\mathrm{sp}}$ and $\mathrm{K} 173 / \mathrm{H}^{\mathrm{sp}} \mathrm{N}^{\mathrm{sp}}$, respectively. On days 3 and 6 p.i., the lungs, heart, spleen, kidneys, liver and brain were collected from mice infected with WSN and WSN/ $\mathrm{H}^{\mathrm{sp}} \mathrm{N}^{\mathrm{sp}}$ $(n=5)$. On day 3 p.i., the lungs of mice infected with the remaining viruses were collected. The organs were homogenized, and virus growth was determined in each tissue by plaque assay on MDCK cells.

To assess the ability of viruses possessing the 1918 virus HA and NA genes to replicate in the central nervous system, we intracranially inoculated 4-week-old BALB/C mice with $6 \times 10^{5} \mathrm{PFU}$ of WSN, WSN $/ \mathrm{H}^{\mathrm{sp}} \mathrm{N}^{\mathrm{sp}}$ or $\mathrm{K} 173 / \mathrm{H}^{\mathrm{sp}} \mathrm{N}^{\mathrm{sp}}$. Brains were collected on day 4 p.i. and homogenized, and virus replication was determined by plaque assay on MDCK cells.

For pathological analysis mice were infected with $10 \mathrm{MLD}_{50}$ of the $\mathrm{M} 88, \mathrm{M} 88 / \mathrm{H}^{\mathrm{sp}} \mathrm{N}^{\mathrm{sp}}$ $\mathrm{M} 88 / \mathrm{H}^{\mathrm{sp}}$, WSN and WSN $/ \mathrm{H}^{\mathrm{sp}} \mathrm{N}^{\mathrm{sp}}$ viruses. After mice were killed on days 3 and 6 p.i., the lungs were removed and fixed in $10 \%$ phosphate-buffered formalin. The tissues were then dehydrated, embedded in paraffin, and cut into $5-\mu \mathrm{m}$-thick sections that were stained with standard haematoxylin and eosin. For viral antigen detection, sections were processed for immunostaining by the two-step dextran polymer method (DAKO), with a rabbit polyclonal antibody to WSN used as the primary antibody.

All animal experiments were performed under an approved animal use document and according to the guidelines of the Canadian Council on Animal Care.

\section{Cytokine/chemokine analysis}

Isofluorane-anaesthetized 6-week-old BALB/C mice were intranasally inoculated with $10 \mathrm{MLD}_{50}$ of $\mathrm{M} 88 / \mathrm{H}^{\mathrm{sp}}$ or $1.5 \times 10^{6} \mathrm{PFU}$ M88. On days 1, 3, 5 and 6 p.i., lungs were collected from three mice infected with each virus and homogenized in PBS. MCP-1, MIP$1 \alpha$, MIP-1 $\beta$, MIP-2, MIP-3 $\alpha$, IL-1 $\alpha$, IL-1 $\beta$, IL-6, IL-10, IL-12 (p40), IL-12 (p70), IL-18, G-CSF, granulocyte-macrophage (GM)-CSF, tumour-necrosis factor (TNF)- $\alpha$, IP-10, RANTES, vascular endothelial growth factor (VEGF), interferon (IFN) $-\alpha$, and IFN- $\gamma$ were detected by enzyme-linked immunosorbent assay (ELISA) (R\&D Systems).

\section{Human serum neutralization assays}

Serum samples were collected between 1998-2001 from donors whose ages ranged from 15 months to $102 \mathrm{yr}$. The sera were treated with receptor-destroying enzyme (RDE) 
(Accurate Chemical and Scientific Corp.) to destroy inhibitors of influenza virus replication. After inactivation of the RDE by treatment at $56^{\circ} \mathrm{C}$ for $1 \mathrm{~h}, \mathrm{WSN} / \mathrm{H}^{\mathrm{sp}} \mathrm{N}^{\mathrm{sp}}$ and K233 were each incubated with twofold serial dilutions of each serum at $37^{\circ} \mathrm{C}$ for $1 \mathrm{~h}$. Remaining infectivity was determined by titration of the samples in a plaque assay on MDCK cells.

Received 28 July; accepted 10 August 2004; doi:10.1038/nature02951.

1. Johnson, N. P. \& Mueller, J. Updating the accounts: global mortality of the 1918-1920 "Spanish" influenza pandemic. Bull. Hist. Med. 76, 105-115 (2002).

2. Reid, A. H., Fanning, T. G., Hultin, J. V. \& Taubenberger, J. K. Origin and evolution of the 1918 "Spanish" influenza virus hemagglutinin gene. Proc. Natl Acad. Sci. USA 96, 1651-1656 (1999).

3. Reid, A. H., Fanning, T. G., Janczewski, T. A. \& Taubenberger, J. K. Characterization of the 1918 "Spanish" influenza virus neuraminidase gene. Proc. Natl Acad. Sci. USA 97, 6785-6790 (2000).

4. Tumpey, T. M. et al. Existing antivirals are effective against influenza viruses with genes from the 1918 pandemic virus. Proc. Natl Acad. Sci. USA 99, 13849-13854 (2002).

5. Tumpey, T. M. et al. Pathogenicity and immunogenicity of influenza viruses with genes from the 1918 pandemic virus. Proc. Natl Acad. Sci. USA 101, 3166-3171 (2004)

6. Oxford, J. S. Influenza A pandemics of the $20^{\text {th }}$ century with special reference to 1918: virology, pathology and epidemiology. Rev. Med. Virol. 10, 119-133 (2000).

7. Lamb, R. A. \& Krug, R. M. Fields Virology (eds Knipe, D. M. et al.) 1487-1531 (Lippincott-Raven, Philadelphia, Pennsylvania, 2001)

8. Wright, P. F. \& Webster, R. G. Fields Virology (eds Knipe, D. M. et al.) 1533-1579 (Lippincott-Raven, Philadelphia, Pennsylvania, 2001)

9. Oxford, J. S. et al. World War I may have allowed the emergence of "Spanish" influenza. Lancet Infect. Dis. 2, 111-114 (2002).

10. Basler, C. F. et al. Sequence of the 1918 pandemic influenza virus nonstructural gene (NS) segment and characterization of recombinant viruses bearing the 1918 NS genes. Proc. Natl Acad. Sci. USA 98, 2746-2751 (2001).

11. Chen, W. et al. A novel influenza A virus mitochondrial protein that induces cell death. Nature Med. 7 , 1306-1312 (2001)

12. Neumann, G. et al. Generation of influenza A viruses entirely from cloned cDNAs. Proc. Natl Acad. Sci. USA 96, 9345-9350 (1999).

13. Goto, H., Wells, K., Takada, A. \& Kawaoka, Y. Plasminogen-binding activity of neuraminidase determines the pathogenicity of influenza A virus. J. Virol. 75, 9297-9301 (2001).

14. Guan, Y. et al. H5N1 influenza: a protean pandemic threat. Proc. Natl Acad. Sci. USA 101, 8156-8161 (2004).

15. Cheung, C. Y. et al. Induction of proinflammatory cytokines in human macrophages by influenza $A$ (H5N1) viruses: a mechanism for the unusual severity of human disease? Lancet 360, 1831-1837 (2002).

16. Hayden, F. G. et al. Local and systemic cytokine responses during experimental human influenza A virus infection. Relation to symptom formation and host defense. J. Clin. Invest. 101, 643-649 (1998).

17. Fritz, R. S. et al. Nasal cytokine and chemokine responses in experimental influenza A virus infection results of a placebo-controlled trial of intravenous zanamivir treatment. J. Infect. Dis. 180, 586-593 (1999).

18. Kaiser, L., Fritz, R. S., Straus, S. E., Gubareva, L. \& Hayden, F. G. Symptom pathogenesis during acute influenza: interleukin-6 and other cytokine responses. J. Med. Virol. 64, 262-268 (2001).

19. Abraham, E. Neutrophils and acute lung injury. Crit. Care Med. 31 (4 suppl.), S195-S199 (2003).

20. Lee, W. L. \& Downey, G. P. Neutrophil activation and acute lung injury. Curr. Opin. Crit. Care 7, 1-7 (2001).

21. Connor, J. S., Kawaoka, Y., Webster, R. G. \& Paulson, J. C. Receptor specificity in human, avian and equine $\mathrm{H} 2$ and $\mathrm{H} 3$ influenza virus isolates. Virology 15, 17-23 (1994).

22. Matrosovich, M. N., Matrosovich, T. Y., Gray, T., Roberts, N. A. \& Klenk, H. D. Human and avian influenza viruses target different cell types in cultures of human airway epithelium. Proc. Natl Acad. Sci. USA 101, 4620-4624 (2004).

23. Gamblin, S. J. et al. The structure and receptor binding properties of the 1918 influenza hemagglutinin. Science 303, 1838-1842 (2004).

24. Stevens, J. et al. Structure of the uncleaved human $\mathrm{H} 1$ hemagglutinin from the extinct 1918 influenza virus. Science 303, 1866-1870 (2004).

25. Francis, T. Jr Influenza: The newe acquayantance. Ann. Intern. Med. 39, 203-221 (1953).

26. Fazekas De St Groth, S. \& Webster, R. G. Disquisitions on original antigenic sin. I. Evidence in man J. Exp. Med. 124, 331-345 (1966).

27. Geiss, G. K. et al. Cellular transcriptional profiling in influenza A virus-infected lung epithelia cells: the role of the nonstructural NS1 protein in the evasion of the host innate defense and its potential contribution to pandemic influenza. Proc. Natl Acad. Sci. USA 99, 10736-10741 (2002).

28. Gambaryan, A. S. \& Matrosovich, M. N. A solid-phase enzyme-linked assay for influenza virus receptor-binding activity. J. Virol. Methods 39, 111-123 (1992).

29. Totani, K. et al. Chemoenzymatic synthesis and application of glycopolymers containing multivalent sialyloligosaccharides with a poly(L-glutamic acid) backbone for inhibition of infection by influenza viruses. Glycobiology 13, 315-326 (2003).

30. Reed, L. J. \& Muench, H. A simple method of estimating fifty per cent endpoints. Am. J. Hyg. 27, 493-497 (1938).

Supplementary Information accompanies the paper on www.nature.com/nature
Acknowledgements We thank D. Dick, A. Grolla, M. Garbutt and S. Jones for assistance with BL4 procedures, M. McGregor and K. Wells for technical assistance, J. Gilbert for editing the manuscript, and Y. Kawaoka for illustrations. This work was supported by a grant-in-aid from the Japanese Ministry of Education, Culture, Sports, Science and Technology, CREST (Japan Science and Technology Corporation), NIAID Public Health Service research grants and Health Canada.

Competing interests statement The authors declare that they have no competing financial interests.

Correspondence and requests for materials should be addressed to Y.K.

kawaokay@svm.vetmed.wisc.edu).

\section{Hedgehog signalling in prostate regeneration, neoplasia and metastasis}

\author{
Sunil S. Karhadkar ${ }^{1,2}$, G. Steven Bova ${ }^{2-4}$, Nadia Abdallah ${ }^{2}$, Surajit Dhara ${ }^{2}$, \\ Dale Gardner $^{5}$, Anirban Maitra ${ }^{2}$, John T. Isaacs ${ }^{3,4}$, David M. Berman ${ }^{1-4}$ \\ \& Philip A. Beachy ${ }^{1,4}$
}

${ }^{1}$ Department of Molecular Biology and Genetics and the Howard Hughes Medical Institute, ${ }^{2}$ Departments of Pathology, ${ }^{3}$ Urology and ${ }^{4}$ Oncology, The Johns Hopkins University School of Medicine, Baltimore, Maryland 21205, USA

${ }^{5}$ USDA ARS, Poisonous Plant Research Laboratory, Logan, Utah 84341, USA

Metastatic cancers adopt certain properties of normal cells in developing or regenerating organs, such as the ability to proliferate and alter tissue organization. We find here that activity of the Hedgehog (Hh) signalling pathway, which has essential roles in developmental patterning ${ }^{1-6}$, is required for regeneration of prostate epithelium, and that continuous pathway activation transforms prostate progenitor cells and renders them tumorigenic. Elevated pathway activity furthermore distinguishes metastatic from localized prostate cancer, and pathway manipulation can modulate invasiveness and metastasis. Pathway activity is triggered in response to endogenous expression of $\mathrm{Hh}$ ligands, and is dependent upon the expression of Smoothened, an essential Hh response component ${ }^{1,2,7}$ that is not expressed in benign prostate epithelial cells. Monitoring and manipulating Hh pathway activity may thus offer significant improvements in diagnosis and treatment of prostate cancers with metastatic potential.

Hedgehog signalling influences development and homeostasis of many gut-derived organs, some of which give rise to $\mathrm{Hh}$-dependent cancers. In the foregut, for example, ligand-dependent pathway activity is required for growth of a significant proportion of smallcell lung cancers and of carcinomas of the stomach, oesophagus, pancreas and biliary tract ${ }^{8-10}$. We consider here the prostate, the site of origin for the second most lethal malignancy in men. The prostate derives from embryonic endoderm that is caudal to the intestinal portal, and which also gives rise to organs such as the colon. Although tumorigenesis in the colon invariably involves Wnt pathway activation, the prostate has recently been found to exhibit a developmental patterning role for $\mathrm{Hh}$ signalling ${ }^{4-6}$ similar to that in the lung ${ }^{3}$.

We examined expression of Hh pathway ligands and endogenous targets in human prostate cancer cell lines by measuring levels of messenger RNA that encode the pathway components GLI and PATCHED (PTCH). Both GLI and PTCH are transcriptional targets of pathway activation with opposite roles in pathway response; GLI serves as a positive transcriptional effector and $\mathrm{PTCH}$ functions to restrain pathway activity by suppressing the action of Smoothened 